Philosophie ANTIQUE

\section{Philosophie antique}

Problèmes, Renaissances, Usages

14 | 2014

Le devoir

\title{
The kathekon
}

A Report on Some Recent Work at Cornell

\section{Tad Brennan}

\section{OpenEdition}

\section{Journals}

Electronic version

URL: https://journals.openedition.org/philosant/748

DOI: $10.4000 /$ philosant.748

ISSN: 2648-2789

\section{Publisher}

Éditions Vrin

\section{Printed version}

Date of publication: 1 November 2014

Number of pages: $41-70$

ISBN: 978-2-7574-0855-1

ISSN: 1634-4561

\section{Electronic reference}

Tad Brennan, "The kathekon", Philosophie antique [Online], 14 | 2014, Online since 01 November 2018, connection on 08 December 2022. URL: http://journals.openedition.org/philosant/748 ; DOI: https:// doi.org/10.4000/philosant.748

\section{cc) (i) (9)}

Creative Commons - Attribution-NonCommercial-NoDerivatives 4.0 International - CC BY-NC-ND 4.0 https://creativecommons.org/licenses/by-nc-nd/4.0/ 
THE KATHEKON:

\author{
A Report on Some Recent Work at Cornell* \\ Tad BRENNAN \\ Cornell University
}

Jacob Klein, a former Cornell student, has recently proposed what I believe to be an extremely interesting and profitable interpretation of the role of indifferents in Stoic ethics. ${ }^{1}$ Klein's proposal is in some ways similar to some positions that I have taken in the past, and so I find it very congenial. But it develops these ideas in a much more precise way, and with consequences that are more radical than anything I had seen. I find it very plausible, although it requires me to abandon certain interpretations that I have published in the past. Its consequences for our understanding of the kathekon in particular are very extensive. With the help of some current Cornell students, I have been exploring the consequences of Klein's proposal. In this paper, I present some of these explorations.

\title{
I. An Introduction to Klein's Proposal: \\ Promotedness as Semiotic Value
}

In several of my earlier publications, I proposed that the kind of value that promoted indifferents possess, their axia, should be understood as having a special restriction to deliberation about the future. ${ }^{2}$ Here are two representative quotations:

...indifferent things like health and disease do have a sort of value called 'selective value' (axia eklektike); we might instead translate it 'planning-

'First I would like to thank the organizers of the journée d'études at the Centre Jean Pépin for their invitation and their kindness, esp. Dr. Wilfried Kühn. Next I thank my students and former students in Cornell who have so many excellent ideas, esp. Jacob Klein, whose views are starting to appear in his own publications. For advice about revising this paper for publication, I wish to thank J.-B. Gourinat and W. Kühn again, who sent me copious and insightful notes. And as always, my deepest thanks go to Liz Karns.

1. Klein 2010.

2. And so for demoted indifferents and their disvalue, apaxia. "Promoted" and "demoted" translate proegmenon and apoproegmenon. Translations that suggest connections to preference in the contemporary sense are bound to mislead, see e.g. Barney 2003, $310 \mathrm{fn} .18$.

Philosophie antique, $\mathrm{n}^{\circ} 14$ (2014), 41-70 
value' in order to bring out the fact that it is only relevant to futureoriented impulses. ${ }^{3}$ When we are already in possession of an indifferent, its 'planning-value' falls out of consideration and the object is purely indifferent; thus we should react with equal equanimity to our possession of health or disease considered as a fait accompli. But when surveying the future, the fact that health has greater 'planning-value' than disease (indeed disease has selective 'disvalue') gives us rational grounds for pursuing health and avoiding disease. ${ }^{4}$

...the kind of value that indifferent things have is a value that matters only for choosing them or avoiding them, selecting them or disselecting them. That means it is a value that they have only in prospect, only when considered as items in the future. Health has some of this value, and more of it than disease does; that's why, other things being equal, it is reasonable for me to select health. But the value it has might be called a sort of 'planningvalue' only; it matters when we are making plans for the future, and disappears when the future becomes the present. It is reasonable for me to take steps today to maintain my health tomorrow, because my health tomorrow has more planning-value today than does my being sick tomorrow. But when it gets to be tomorrow, the 'pay-off values of my health and sickness are the same: they are both completely indifferent. ${ }^{5}$

Klein's own work approached the question of axia from a different problematic: he wanted to clarify the relation of indifferents to our pursuit of happiness as our end. In particular, Klein argues against the view that promoted indifferents have a kind of value that is either teleologically independent of our happiness, or is instrumental to our happiness. Indifferents cannot have a kind of value that is independent and autonomous of happiness: that is ruled out by the Stoic claims that happiness alone is our end, and that this is the thing for the sake of which we do everything. On the other hand, the value of indifferents cannot be instrumental in the sense of bringing about, contributing to, or constituting some portion of our happiness through our possession of them. This would make our failure to possess them or acquire them destructive of our happiness. Both of these views, he argues, are incompatible with the Stoics' fundamental conviction that happiness alone is our end, and that virtue is sufficient for it.

But if a promoted indifferent is neither worth pursuing independently of some relation to happiness, nor instrumental to happiness, then how should we understand the rationality of pursuing it? The Stoic doctrine of the end tells us that we have reason to pursue things whose possession can

3. Stobaeus II 83,13-84, 1 (SVF $3.124=$ LS 58D). The term is attributed to Antipater, but I take it to represent Chrysippean doctrine.

4. Brennan 2003, p. 263-264.

5. Brennan 2005, p. 101. 
contribute to or constitute our happiness. If something is good, whether intrinsically or instrumentally, its goodness is a reason to pursue it. But what reason can there be to pursue things that make no contribution to our good?

Klein's very radical proposal is that we should understand indifferents as giving us reasons of a different sort, what he calls "epistemic reasons". Typically, we think of valuable things in the world as giving us reasons to act. But epistemic reasons are, in the first instance, reasons to believe, rather than reasons to act. ${ }^{6}$ And Klein's proposal is that information about promoted and demoted things around us gives us reason to believe propositions about what we should do. The value of food or health is not a reason to possess it. Rather, it is a reason to believe that we should pursue it. ${ }^{7}$

Because I find the language of "reasons" somewhat artificial and hard to understand, I want to present Klein's proposal in different terms. Klein, I think, can be understood as proposing that selective value is semiotic value. Every indifferent item that we consider, when deciding what to do, gives us signs and indications, pointing us towards some actions and away from other actions. The fact that food is a promoted indifferent is an indication-in itself, perhaps, only a weak one-that I ought to pursue it. The

6. Klein 2010, chapter 4, p. 37: "preferred and dispreferred indifferents do not enter into the deliberations of the Stoic agent as practical objectives at all."

7. But are there not some promoted indifferents that cannot be construed in this way, because they cannot be made the objects of choices? Good birth (eugeneia) for instance: how can I make any choice that could affect whether my parents were noble or not? Ian Hensley (a member of my seminar) has suggested that I might select good birth for my children, by selecting the right sort of mate. Another kind of answer is attested for some Stoics in Stobaeus 2.107, 14-108, 4, where we are told that both euphuïa and eugeneia can arise from practice and training (melete, kataskeue). A good nature or a good birth (reinterpreted, as so often in Stoicism) will be whatever state of your character gives you an aptitude for acquiring virtue. And this is both an indifferent (since it is only a potential for virtue, not virtue itself), and also something that one can pursue. That disposes of the potentially problematic cases of engeneia and euphuia; but what if there are other indifferents that seem incapable of change through our actions? Certainly (not speaking as Stoics now) we can conceive of personal characteristics that are 1) indifferent in being irrelevant to virtue; 2) nonetheless preferable in some weaker sense; but 3 ) immune to change by any action on the part of the agent. E.g., having a perfect ear for pitches: that is an agreeable or desirable thing to have, even if it is indifferent so far as virtue and happiness go. But if it is an immutable personal attribute, then there is no action I can take towards having it. Would the Stoics have called this a promoted indifferent? No; not if we can trust D.L. 7.104 and Stobaeus $2.82,8-10$. For there, the stimulation of horme, and ekloge in particular, are made essential to the indifferents that are promoted and demoted (as opposed to the hapax adiaphora). What cannot result in action is not a horme, and what I cannot hope to change, I cannot have a horme towards. (A mere velleity, I think, would not count as a Stoic horme). So anything that is non-contingent (e.g. the identity of my ancestors) cannot be a promoted indifferent. 
fact that eating when I have a fever is likely to make me more sick, and that illness is a demoted indifferent, is an indication-again, only a defeasible one-that I should not eat.

This proposal fits very well with the idea that whatever value promoted things have is strictly limited to future-tensed considerations. There is no value in possessing them, other than the value that they have for informing our deliberations about what to do in the future. They have value as signs and indications of what we should do, but (whether we interpreted them correctly or not) that value becomes irrelevant after we have made our decision and acted. ${ }^{8}$ This much of Klein's proposal I had already anticipated.'

But Klein observes, in addition, that this makes a fundamental change to the way that we think about the role of aggregation and trade-offs in deliberation. If the kind of value that promoted indifferents have depended on our eventual possession of them, then our deliberation might take the form of a maximizing calculation: act so as to maximize the amount of value in the outcome. We would consider alternative courses of action, calculate (through some metretic art) which course would produce the greatest net value, and pursue it for that reason.

But if we think of the value as semiotic value, then the comparison of alternative plans is a different kind of activity: it is the examination of evidence, in order to see where the preponderance of evidence lies. And this

8. W. Kühn helped me to clarify several points here. In the quotes above from Brennan 2003 and 2005 I said that indifferents lose their axia when I come to possess them, and this is wrong. I was confusing two questions: 1) when I come to possess some promoted or demoted indifferent, do I now have anything that I should place non-epistemic value on? (answer: no); 2) do the promoted or demoted indifferents that I come to possess still have some epistemic value even after I possess them? (answer: yes). It is clear (from, e.g. Cicero's de fin. 3.60) that when I deliberate about the future, I consider both the indifferents that I can aim for in the future, and the indifferents that I currently possess. Both kinds, the present and the future, are informative and significant about what it is reasonable for me to do in the future. But of course when I possess some health in the future, this has no more nonepistemic value than when I possess some disease in the future-neither makes me happier or more miserable, makes my life more or less complete, or gives me any greater cause for satisfaction or regret. They are, to that extent, equally indifferent. But this does not mean that their value for deliberation is indifferent: they have different informational content, and suggest different courses of future action. My current illness, e.g., may give me more reason to think that suicide is reasonable. Once we have said that axia eklektike is semiotic or epistemic value, there is no reason to deny that the indifferents already in my possession still have value of this sort.

9. In Brennan 1999, I wrote, "[E]ven if the Sage is an infallible discoverer of virtuous acts, that is because he is an infallible tracker of the divine mind, not because his decisions are an originating source of new ethical facts. What ${ }^{*}$ makes* it the case that it is the ethical thing to do is something strictly over and above the Sage's deliberations, e.g. the mind of God and the state of the cosmos. It's just that the Sage's deliberations about indifferents were exactly the medium through which he discovered this fact about the mind of God." 
changes how we think about the interaction between positive and negative. In a maximizing exercise, the desirability of an outcome must take into account any negative consequences that are produced, and subtract them from the positive consequences. Perhaps selling the furniture in order to buy food was, when all of the alternatives are considered, the best course of action to pursue. But the loss of the furniture still detracts from the goodness of the outcome. We may feel that we have reason to regret the loss, or think that an outcome that allowed us to acquire food and retain our furniture would have been even better than any of the alternatives available to us.

When we consider signs and evidence, however, there is no such persistent loss after they have played their role. Suppose that we are trying to divine the location of our car-keys. There are various signs that point to their being in the bedroom, and other signs that point away from their being in the bedroom. Prior to the discovery of the keys, these signs must be weighed against each other, and the weight of evidence in one direction does tend to diminish the weight of evidence in the other direction. But that canceling effect ends when the keys are found. Once we have found our keys in the bedroom, led there by the preponderance of evidence, the contrary signs that suggested they were elsewhere do not retain any force, or diminish the force of the signs that led us to the discovery. ${ }^{10}$ Nor is there any sense in which we might regret that the discounted signs turned out to be false, or think that it would have been better somehow if all of the signs, both those pointing towards the bed-room and those pointing away from it, could have been simultaneously true. ${ }^{11}$

Consider how this affects our understanding of the pursuit of indifferents in Stoicism. We know that food is a promoted indifferent, and health is a promoted indifferent; each has some value, and that value acts as an indicator, in typical cases, that we should pursue the acquisition of food and of health. ${ }^{12}$ However, in some cases the doctor will explain to us that

10. It does not follow that we have discounted the value of an entire class of signs; other signs very like the signs that turned out to be wrong in this case may well be reliable in future cases.

11. There is a different phenomenon that should not be confused with this, in which we do have a positive desire that the discredited signs should somehow be accounted for. Typically, e.g., I leave my keys with my glasses, and my glasses were in the front hall; that was one of the reasons I thought my keys were not in the bedroom. This anomaly might prompt me to look for an explanation: how did my keys come to be separated from my glasses? But wanting the discredited signs to be explained or accounted for is not the same thing as wishing that both sets of signs, somehow, could have turned out true.

12. J.-B. Gourinat pointed out to me that the standard lists of promoted indifferents contain such items as health, wealth, and life, but do not mention food. He wondered whether it is a category mistake-or even a vice-to treat food as a promoted indifferent. I think 
we should fast in order to recover our health. For the meanwhile, that is, we cannot simultaneously acquire both food and health. If we think that the axia that these two promoted indifferents have is some kind of possessionvalue, then we will feel that our situation is an unfortunate one: no matter what we do, feast or fast, we will wind up acquiring less possession-value than if we could have both food and health simultaneously. But if we think of their axia as semiotic value, then we think of the general promotedness of food and health as incomplete and defeasible signs directing either to eat or not to eat, as the further details of the case may go. Once we use them in our deliberations to figure out what it is that Zeus bids us to do (eat, say, and forgo our health), then we do not think of the resultant situation as one in which we have less of any value than we could have had. The value of health was exhausted by its role in giving me information about the will of Zeus, its semiotic value. In this case, it turned out to be a misleading indicator, like some piece of evidence suggesting that my keys are in the hallway, when they are actually in the bedroom. After I have discovered what to do, and discovered that pursuing my health was not the thing to do, I can dismiss considerations of health (in this case) as I would dismiss a misleading piece of evidence. The possession-values of food without health, health without food, and both food-and-health together, are all equal: they have no possession-value whatsoever. Accordingly, we have no reason to regret our current situation, or to think that fate has cheated us of anything worth having. ${ }^{13}$

there is sufficient evidence of an indirect kind to allow us to feel confident that food is a promoted indifferent. In many of our sources, we learn that indifferents (or promoted things or things according to nature) can be divided into those that are promoted etc. through themselves (kath' hauta), and those that are productive of the first kind (poietika) or are promoted etc. through other things (di' hetera). See Stobaeus 2.80,14 and 2.82, 20; D.L. 7.107; Cicero de Fin. 3.20 and 3.56 (partim per se ipsa praeposita, partim quod aliquid efficiunt; aut ipsum secundum naturam sit aut tale quid efficiat). We are told that health is promoted in and through itself, and although we are never told what things are productive of health, it seems a safe inference that food would be among those things. I suspect that the distinction in Epictetus 2.6.9 between the things that are according to nature and the things that are more naturally suited towards the acquisition of those things that are according to nature may also be a distinction between the per se promoted indifferents and the productive or instrumental promoted indifferents.

13. Both W. Kühn and J.-B. Gourinat objected to my invocations of the will of Zeus, Kühn in particular because "la volonté de Zeus n'est accessible qu'au sage," whereas all agents need to deliberate about what it is kathekon to do. I agree that only Sages have knowledge, but I think that even non-Sages can have some weaker kinds of access (e.g. true belief, well-supported belief, or even katalepsis) to the will of Zeus. For instance, anyone who accepts the Stoic doctrine of divine determinism can see that it was the will of Zeus that it should rain yesterday-rhechthen de te nepios egno. And while only Sages have the knowledge of physics, any progressor may acquire more and more true beliefs, and even kataleptic beliefs, about the natural world; and learning about what happens by nature is equivalent to 


\section{The Consequences for the Theory of Impulse}

That's a brief sketch of Klein's proposal, though more details will emerge. And my initial reaction was to reject the proposal, because it conflicted with a different view that I have espoused in the past-wrongly, as I now think. This is the view that every impulse in Stoicism, every horme, has two parts. In one part, the horme mentions an evaluative term such as "good", "bad", "promoted" or "demoted". And in the other part, the horme asserts that it is right or necessary or kathekon to respond to that value in some way, e.g. by pursuing or avoiding it.

There is good evidence that this two-part analysis applies at least to the emotions (pathe) of pleasure (hedone) and pain (lupe). We are told by Andronicus (SVF 3.391), for instance, that pain is "an irrational contraction; or a fresh opinion of a present evil, at which they think it necessary to contract," and that pleasure is "an irrational elation, or a fresh opinion of a present good, at which they think it necessary to be elated." Stobaeus (SVF 3.394) tells us, similarly, that pain is a "contraction of the soul that is disobedient to reason, and the cause of it is believing that a fresh evil is present at which it is appropriate (kathekei) that one contract," and that pleasure is "an elation of the soul that is disobedient to reason, and the cause of it is believing that a fresh good is present, at which it is appropriate (kathekei) that one be elated." 14 (Note, since the point will come up again, the presence of the word "kathekon" in the definition of the emotions). ${ }^{15}$

Each of these emotions, then, is a belief that something is a good or bad, of such a sort that one believes, in addition, that one should be elated or should contract in response to it.

learning about the will of Zeus. D.L. 7.87-88 tells us that when we live in accordance with nature, we are living in accordance with the nomos koinos, and with the orthos logos, and that this is the same as Zeus. I prefer to describe things in terms of the will of Zeus (despite my personal preference for laïcité) both because it is more vivid, and because it emphasizes certain historical continuities with theological ethics as it occurs in e.g. Socrates and Plato. But any reader who wishes to replace all references to the will of Zeus in my article with references to what happens in accordance with nature should feel free to do so.

14. There are many details here that deserve greater scrutiny, but are not relevant to this paper. E.g., the text in Stobaeus makes it look as though "prosphaton" modifies kakon and agathon. It would be awkward to take it adverbially with the infinitive "doxazein". And yet, Galen's quotations of Posidonius make "prosphatos" modify the noun "doxa" (SVF 3.463, 481). Is it the opinion or the evil that is fresh? Secondly, there is a very significant difference between Andronicus' formulae, in which the pathos simply is the doxa, and Stobaeus formulae, in which the doxa is the cause of the pathos. All of this I must defer for another time.

15. Cicero's definitions in the Tusculans $(4.7,14)$ are close translations of these, e.g. "est ergo aegritudo opinio recens mali praesentis, in quo demitti contrabique animo rectum esse videatur". 
We are told that pleasure and pain have the two-part structure, and also that they can be described simply as "irrational elation" or "irrational contraction". The other two emotions-desire and fear-are not explicitly said to have the two-part structure, but they are explicitly described as "irrational pursuit" and "irrational avoidance," and on the basis of this I have assumed that they could also be given two-part analyses to match the twopart analyses of pleasure and pain. ${ }^{16}$ (If the shorter descriptions can be expanded in the case of pleasure and pain, then why not in the case of desire and fear?) The eupatheiai are also described as "rational elation", "rational pursuit", and "rational avoidance", and said to be the "opposites" of the emotions. On this basis, I have assumed that each of the eupatheiai also has the two-part structure.

Finally, I assumed that selection and disselection, since they are impulses, would have the same two-part structure that I had attributed to the other impulses. ${ }^{17}$ But in their case, the impulse would be a belief that these things were promoted or demoted indifferents, instead of beliefs that they were good or bad.

As should be clear, there were many steps of interpretive interventionassumptions, simplifications, and regimentations - in this line of thought. The reward was a regular, orderly, and systematic account of impulse, which (it seemed to me) respected a central tenet of ancient action theory, that action only emerges from evaluation. Rational pursuit, or any voluntary, intentional pursuit, is a response to the antecedent perception of value. The purest form of this tenet is found in the Socratic dictum that desire is for the good. The suggestion that selection is for the promoted-i.e. that the impulse of selection only arises as a response to a perception of a sort of analogue of goodness, sc. promotedness-seemed to me a modest, minimal

16. E.g. in Brennan 2005, p. 98.

17. And yet even for the claim that ekloge and apekloge are hormai, there is less direct evidence than I would like. D.L. 7.104 says that promoteds and demoteds are "stimulative of horme and aphorme, which is why the one group are selected (eklegetai), and the other disselected (apeklegetai)." In the famous Foot Fragment (Epictetus 2.6.9), Chrysippus seems to contrast his being eklektikon of health with his having a horme for illness, in a way that makes most sense if ekloge is a kind of horme. (That remains a plausible inference even if Chrysippus is here using the verb horman to refer to a species of impulse, not to the entire genus of impulse. He would still be contrasting a species of impulse, directed towards illness, with ekloge directed towards health.) Plutarch $(1071 \mathrm{~A}=$ SVF 3.195) treats ekloge and lepsis as similar terms, and Stobaeus (2.75 = SVF 3.131) in turn treats lepsis as analogous to hairesis, which is certainly a kind of horme (Stobaeus $2.87=$ SVF 3.173) On the whole I think it is a fairly safe inference that ekloge is a kind of horme; but it would be nice to have more secure evidence. W. Kühn reminded me that " $\varepsilon \kappa \lambda \circ \gamma \eta \dot{\eta}$ ne figure pas dans la liste des espèces de l'impulsion pratique, que transmet Stobée II 87, 14-16," but I do not take this as strong evidence for or against. That list is far from exhaustive-we know of many subspecies of impulse that are not included in it. 
development of that dictum, which respected its essential spirit, and so respected the Central Tenet, that rational action is the outcome of evaluation.

But my previous accounts of impulse must be wrong if Jacob Klein's proposal is right. And I am currently inclined to think that they are wrong, at least so far as selection goes. ${ }^{18}$

Here is the source of the conflict. Jacob thinks that axia constitutes a reason for belief, rather than a reason for action: seeing that the food is a promoted indifferent gives me reason to believe I should pursue it, instead of giving me reason to possess it. The only value that promoted indifferents have is their value as signs and indicators of what I should do, but I do not gain anything "of value" (in the non-epistemic sense) by possessing them. But he also thinks that, in some way, judgments about axia do result in impulses: if the indication given by the food is not counter-indicated by any other signs, then I will have an impulse to eat. And my Central Tenet claims that if an impulse eventuates, then an evaluation-i.e. the attribution of non-epistemic value-must have occurred. If I believe that I should pursue it, then this "should" must supervene on some sort of antecedent evaluation: perhaps the evaluation that the food is a good thing, or that the food is a promoted thing, or perhaps some new value other than goodness or promotedness is brought into play-that is not ruled out by the Central Tenet. But the Central tenet does demand that impulses supervene on attributions of value of some non-epistemic kind. ${ }^{19}$ If I have a belief that I should pursue $\mathrm{X}$, then this must be a belief whose real structure is believing that $\mathrm{X}$ has some value $\mathrm{V}$ of such a sort that $\mathrm{I}$ should pursue $\mathrm{X}$ because of its $\mathrm{V}^{20}$

This in turn means that Klein's treatment of axia as a "reason to believe" rather than a "reason to possess" simply means that our belief must be the belief that there is some further, additional "reason to act", some further value. The further value won't be goodness or badness, because the objects in question are indifferents pursued as such. And the further value won't be promotedness or demotedness, since those are being treated epistemically as signs, rather than as (non-epistemic) values. What, then, is the new value on which the impulse supervenes? And furthermore, how will

18. For the present, I am still inclined to think that the pathe and eupatheiai do all have the two-part structure that is attested explicitly for pleasure and pain.

19. "Value" here not as a translation of axia, but as a category including good, bad, promoted, demoted, and any other properties relevantly like them.

20. Or alternatively, the belief must be the conclusion of an argument that has some other beliefs about value among its premises. 
this new value succeed in avoiding the dilemma ${ }^{21}$ that Klein posed for the older interpretation of promoted axia?

So if we hold on to the Central Tenet, then the Klein proposal seems idle; it says "the object's axia is not the value on which selection supervenes; it is instead a sign that the object has some other, hitherto unknown value on which selection supervenes." If that were what the proposal amounted to, then it would be wiser to keep life simple by making axia the base for the supervenient impulse to begin with, i.e. it would be better to reject the Klein proposal right away.

Conversely, if we want to give Klein's proposal serious considerationand I think we should - then it is worth considering that the Central Tenet may simply be wrong. It may not be necessary, in Stoicism, for an impulse to start from an attribution of non-epistemic value. The thought that I should eat the food may not need to depend on an antecedent thought that the food is good, or desirable, or important to have. Perhaps the entire content of the impulse can simply be, "I should eat this food". Of course, when I have a vicious desire (epithymia) for the food, then my impulse to eat it does obey the Central Tenet: my thought that I should eat the food is the consequence of my false belief that this food is a good. ${ }^{22}$ My thought that I should fear death is a consequence of my false belief that death is an evil. Those impulses clearly involve evaluations, i.e. attributions of nonepistemic value like goodness and badness. But those may be features of pathe that are not shared by selection and disselection, and that are not essential to impulse.

And indeed, once we ask ourselves what is essential to impulse, it looks as though our best evidence does not give any support for the Central Tenet. That best evidence is the famous statement in Stobaeus (2.86) that "what stimulates impulse is nothing other than (ouden heteron all' e) a hormetic impression of the kathekon, simpliciter (autothen)." Seen in light of the current discussion, this text speaks very strongly against the Central Tenet. An impulse does not require an impression that something has a value of this or that sort: all that it requires is an impression that something is kathekon. The impression that some action is kathekon, all by itself and ipso facto (autothen) is sufficient to generate an impulse to perform it. ${ }^{23}$

21. I.e., that if it makes a contribution, even instrumental, to happiness, then it is not properly indifferent, whereas if it is independent of the good then it violates the Stoic tenet that all rational action is directed to the unitary end of happiness.

22. I.e. on the assumption that epithymia has a two-part structure of the sort that is explicitly attested for lype and hedone.

23. If and only if one assents to the impression, of course. The impossibility of an impression producing an impulse without assent is exactly the point that the Stoics argued against the Academics, as Plutarch tells us (1057A = SVF 3.177). Presumably the phrase "to 
Accordingly, my acceptance of Klein's proposal about indifferents commits me to abandoning my previous views about selection, and impulse in general. It is possible for me to have a belief like 'I should eat this food', without there being, anywhere in the impulse, some ascription of value to the food. Accordingly, when I take the promotedness-value, i.e. the axia, of the food as a sign that I should eat it, I am not taking it as a sign that there is some further value that underlies the obligation. The mere thought that I should eat it, that kathekei moi phagein, is all by itself (autothen) sufficient for an impulse. ${ }^{24}$ Conversely, it is possible to judge that something is a promoted or demoted indifferent, i.e. has some axia or apaxia, without thereby having an impulse to select or disselect it. This direction of separability will prove important in thinking about deliberation.

\section{The Consequences for Deliberation}

If axia eklektike is semiotic value, then how do Sages deliberate? They look for signs of Zeus' will, in order to figure out what Zeus commands them to do. In general, they will observe many signs, and have to weigh them against each other to see what is the most probable conjecture to make about Zeus' command. ${ }^{25}$ The weighing of signs, I argued above, is different from a metretic art of the sort outlined in the Protagoras, which attempts to maximize the value of a resultant state of affairs. Instead, this weighing seeks the preponderance of evidence, and it seems to be called parametreisthai.

There are two main classes of evidence the Sage considers, as well as two sources of background knowledge against which to interpret them. The

de kinoun ten hormen" must mean something like "what initiates the sequence that (after an assent) results in an impulse..."

24. In Brennan 2005, p. 225-226, I noted that discussions of kathekonta that make no explicit references to value are not only found in Stoicism, but become more and more central to the topic as time goes by. But I still took them to be elliptical for "phi' ing has or provides the most value, and in virtue of that value I should do it." I.e., I was still assuming the Central Tenet.

25. W. Kühn noted that any talk of "conjecture" must be shown to be compatible with the Stoic doctrine that the Sage never opines, i.e. never assents to any impressions that are not kataleptic. In what follows, I use "the Sage conjectures that P" as a shorthand for "the Sage assents to a kataleptic impression that the preponderance of evidence shows that it is reasonable that P." So this is not a kind of conjecture that involves any partial doubt, or any likelihood of being wrong. When the Sage conjectures that Zeus commands him to eat (i.e., assents to the kataleptic impression that it is reasonable that Zeus commands him to eat), then he does not assent in any way to the impression that Zeus commands him to eat. That, after all, might be wrong-perhaps it will turn out that he does not eat. But he does assent to its being reasonable that Zeus commands him to eat, i.e. to there being a preponderance of reasons to believe that Zeus commands him to eat. And this is something that he can know. 
promoted and demoted things that they can see or anticipate-health, illness, food, and so on-are the signs that they use most often. ${ }^{26}$ And the body of knowledge that is used in interpreting these signs is their experience of what happens by nature, the empeiria ton physei sumbainonton that Chrysippus refers to in his account of the telos (DL 7.87). As a second class of signs, or perhaps a subclass of this first one, Sages also consider the social relations that they bear to others, and which others bear to them. ${ }^{27}$ Epictetus probably overstates the case when he says that kathekonta are parametrized "for the most part" (hos epipan) by our relations (scheseis); the knowledge of non-social nature and non-social promoteds such as food and health must be at least as frequently invoked as our knowledge of social relations in helping us to divine the will of Zeus. The consideration of scheseis is also, I think, a matter of semiotics: the relations that I bear to other people are indications of what Zeus commands me to do. Epictetus 3. 11.4-6 tells us that Zeus is the epoptes of such scheseis as "father", "brother", "guest", and "kindred" in general, and that I should apply the lines of Homer to these cases, saying "I may not dishonor a father, for all fathers belong to Zeus Patroios." The knowledge used here, i.e. the knowledge of human relations in general, is presumably one part of the general knowledge of nature that Chrysippus refers to.

Finally, there may be occasions when the Sage uses unsystematic signs. Brunschwig notes that "parfois... [le sage] interprète un événement particulier comme un signe divinatoire," and illustrates this with the story of Zeno's death, when Zeno fell, broke his toe, and said "I am coming! There is no need to yell!" 28 Brunschwig asks why Zeno interpreted his fall as a warning from destiny, rather than an unremarkable accident. I want to suggest that we need not choose between these models. Zeno could have arrived at the same decision by treating all of the events as indifferents: he observes that he is losing his ability to maintain his balance, that he has suffered an injury to his foot. These are both demoted indifferents, and they will lead to more demoted indifferents in the future, particularly when considered in light of his age. This is the sort of situation that Cicero describes in de Finibus 3.60, in which someone has in the present and foresees in the future a preponderance of things contrary to nature, and for that reason it

26. Stobaeus 2.86, 12-16 tells us that kathekonta are parametrized by indifferents, sc. the natural and contrary to nature. Plutarch $1042 \mathrm{D}$ tells us that we should deliberate about suicide by parametrizing not with goods and bads, but with mesois. Plutarch 1063D similarly says that suicide is parametrized by the natural and the contrary to nature. Stobaeus $2.110,9-15$ gives us the same doctrine, I think, but in slightly misleading terms, when it says that suicide is parametrized "tois kathekousi kai tois para to kathekon".

27. Encheiridion, 30. (In using the word "epoptes" he may also be thinking of the Homeric tag "Eeliou, hos pant' ephora...")

28. Brunschwig 2005, p. 371 fn. 32. 
is their officium to depart from life. ${ }^{29}$ The fall and the injury are, at the same time, both banal indifferents and warnings from destiny, because all indifferents are divinatory signs.

To see in more detail how deliberation works, let's try it first for a simple case in which the Sage is faced with an uncomplicated choice between eating food and not eating food, and there is only one sign to be taken into consideration. I owe to two of my current students, Katie Mathie and Brandon Conley, the suggestion that the steps in deliberation should be reconstructed as follows:

1) I am a human being and I need food.

2) Zeus usually and in most cases wills that human beings eat food when they need food.

3) Here is some food, which is a promoted indifferent.

4) The presence of this food is a defeasible sign that Zeus commands me to eat this food.

5) (As a conclusion from 1-4) it is reasonable that Zeus commands me to eat this food.

6) If it is reasonable that Zeus commands me to eat this food, then it is kathekon that I eat this food.

7) It is kathekon that I eat this food.

The final step of this simplified practical syllogism is an impulse to eat the food. On the understanding of selection that I now accept (i.e. selection without evaluation), the final step is an instance of the impulse of selection: I select the food..$^{30}$

29. I also want to connect the preponderance of promoted and demoted objects in Cicero (in quo plura sunt...quae secundum naturam...in quo aut sunt plura contraria aut fore videntur...) with the preponderance in the definition of the eulogon axioma as "to pleionas echon tas aphormas..." (DL 7.76 = SVF II.201). If Klein is right that axia is semiotic value, then a preponderance of promoteds or of axia in those promoteds is a preponderance of reasons to believe I should pursue.

30. J.-B. Gourinat objected to this analysis on the grounds that talk of "practical syllogisms" is more Aristotelian than Stoic. While I cannot answer this objection directly, I do think that it touches on some very deep issues about how one understands the Stoic project of rational psychology. I have always assumed that the Stoic doctrine of rational presentations was motivated in part by the belief that adult human agents reason in ways that can be studied by Chrysippean logic. More than that: representing human rationality in this way involves no distortion of the psychological facts, but rather an exact encapsulation of the content that is already causally at work in people's actions. When we analyze the action of a squirrel in pursuing a nut by attributing a practical syllogism to it, then we are engaged in rational reconstruction that fundamentally misrepresents the content of the squirrels (subrational) impressions and impulses. But when we do the same for a human being, there is no misrepresentation and no distortion. Rational re-construction here is the literal recovery of something that was constructed rationally the first time. Rationality is built right into human psychology: what our practical syllogisms do is not to force vague and ambigu- 
There are three general structural criteria that a successful reconstruction of deliberation must satisfy:

K) Each of the beliefs that the Sage has in the course of the deliberation must be an instance of knowledge, i.e. a strong assent to a kataleptic impression.

I) The correctness of the Sage's action must be immune from the failure of their efforts. If they decide to eat, for instance, and then for some reason beyond their control they fail to eat, then it must remain true that they performed a correct action, a katorthoma.

P) It must also be possible for the account of deliberation to succeed, mutatis mutandis, for a non-sagacious Progressor, i.e. it must be possible to construct an ideal Progressor's deliberation that satisfies a principle $\mathrm{K}^{*}$, according to which the beliefs are katalepseis, and a principle $\mathrm{I}^{*}$, according to which their action is an imperfect kathekon, but still immune to reversal.

$\mathrm{K}$ ) is satisfied, I think, because the first four premises are either particular present-tensed perceptual episodes (premises $1 \& 3$ ) which are candidates for direct kataleptic impressions, or they are theorems of physical science (premises $2 \& 4$ ), i.e. the Sage's empeiria, which in turn will be instances of katalepsis for the Sage or for the non-Sage who has made sufficient progress in studying nature. The content of 2 is suggested by, e.g., Chrysippus apud Epictetus (2.6.9), saying "God has made me selective of such things". Chrysippus did not have knowledge of the contents of this claim, of course, because he was not himself a Sage. But as a student of nature, he can gather more and more evidence and learn more and more about the working of nature (e.g. how Zeus has made human beings and their instincts), so that he can have kataleptic impressions with contents of this sort.

Premise 5) is a judgment that a proposition is reasonable, eulogon. The inner proposition, that Zeus commands me to eat this food, is not itself the content of a kataleptic impression. And the Sage does not assent to it. It may be false. Zeus may, as it turns out, command that I not eat the food (as I shall learn if I fail to eat the food). But the majority of signs point towards its being true; it has, as the definition of a eulogon axioma says, "the preponderance of its aphormai in the direction of being true." ${ }^{31}$ Accordingly,

ous impressions into a regimented form, but to report exactly what occurred inside a mind that is rational in its very depths. This is how I understand the Chrysippean project, but of course the disagreement between Prof. Gourinat and myself here is a very deep one about the historiography of Stoic philosophy, and cannot be settled in a footnote.

31. DL 7.76 = SVF II.201. This use of "aphorme" must be different from the sense in which it is the counterpart of "horme". It is also probably different from, but perhaps related to, the sense in which an aphorme is some sort of innate predisposition to formulate conceptions (e.g. SVF 2.988.21, 3.214.22-23; 3.228.10). 
the judgment "it is reasonable that Zeus commands me to eat this food" will remain true, even if the inner proposition turns out to have been false. And this judgment will be a katalepsis, when a Sage or a sufficiently advanced Progressor makes it.

Premise 6) is simply an instance of the general definition of the kathekon, and so something that can be known by a Sage or made the content of a Progressor's kataleptic judgment. That definition says that an action is kathekon if it has a reasonable justification or defense (apologismos/ apologia). And this action of eating does have a reasonable defense: Zeus commanded me to perform it. (More below on why this constitutes a reasonable defense). So the general definition-knowledge of which is presumably part of what the Sage knows about ethics-licenses all of the substitution-instances of "if it is reasonable that Zeus commands me to phi, then it is kathekon that I phi." Accordingly, this too is something that the Sage can know.

And the conclusion, 7), simply follows from $5 \& 6$ by the modus ponens. I assume that it is possible to have a kataleptic impression of the conclusion of an argument whose premises are kataleptic. ${ }^{32}$

The example above was designed for simplicity. Complexity would come by multiplying premises 1 through 4 above. Instead of noting the presence of a single promoted indifferent, a complex deliberation would have separate premises for each of the relevant indifferents or things according to or contrary to nature, present and prospective, that the Sage had to consider. Some of the references to future indifferents would themselves be embedded within reasonable-operators (e.g. 'it is reasonable that I shall be alive tomorrow'). Instead of noting only one fact about the agent (sc. "I am a human being"), it might note the many social roles that the agent fills. And then each of these observations about indifferents or roles would be treated as a sign, in a separate premise that recorded knowledge of natural science or knowledge of politics (broadly speaking): the fact that I am a son is a defeasible sign that Zeus commands me to phi; the fact that I am a citizen is a defeasible sign that Zeus commands me to psi; and so on.

Then there is the step from those many considerations, to the conclusory judgment in premise 5 (or premise $2 \mathrm{~N}+1$, in a deliberation that involved $\mathrm{N}$ indifferents or roles). The Sage considers the many promoted and demoted things that could be pursued and avoided by various possible actions, and the various roles that they and others stand in to one another, and in light of all of these considerations, plus their knowledgeable experience of nature, arrives at an overall, all-things-considered judgment about

32. Sextus, $A M$ 8.396-410, shows that the Stoics recognized kataleptic impressions of demonstrations (apodeixeis), which are incorporeal. 
what it is most probable, most reasonable, that Zeus commands them to do. Each of these signs presumably counts as an aphorme, of greater or lesser weight, in the determination of where the preponderance of aphormai lie, in virtue of which "Zeus commands me to phi" will be a reasonable proposition. ${ }^{33}$

How this assessment of preponderance takes place I do not know, and my failure to say more here may seem to render the account vacuous. It may be that the Stoics would agree with Aristotle that universal rules must cede to the particular perceptions of an expert, so that nothing more can be said in the abstract. But although my ignorance requires me to leave a lacuna where the Sage's actual ratiocination occurs, the outline of deliberation that I have offered is far from empty. It has enough substance to solve problems and give insights if it is right, or to be false if it is not. It also has enough substance to be incompatible with some other proposals-my own earlier proposals among them, as we shall see.

Those reflections show why I think the Mathie-Conley reconstruction satisfies principles $\mathrm{K}$ and $\mathrm{K}^{*}$. I believe this reconstruction also makes the Sage's katorthomata, and the non-Sage's kathekonta, immune from reversal by the failure of their efforts, thus satisfying I and $I^{*}$. No future event, including the failure to obtain the object of their impulse, renders any of their judgments false, or makes the reasonable judgment any less reasonable (even when it turns out to be false)..$^{34}$

The Sage's conjecture about Zeus's command remains reasonable (and thus their belief that the conjecture was reasonable remains true) even

33. Note that the Sage never needs to assent to "Zeus commands me to phi." They can move straight from "it is reasonable that Zeus commands me to phi," to "therefore, it is kathekon that I phi", without ever assenting to the claim that Zeus does in fact command them to phi.

34. And reasonable judgments differ from kataleptic ones in that the kataleptic are unfalsifiable, whereas the reasonable ones can turn out otherwise, sc. false (Athenaeus 354E $=$ SVF 1.624). To rehearse some material from Brennan 1996: a reasonable judgment is a judgment like "I shall be alive tomorrow", said by someone who has overwhelming reason to believe that they will be alive tomorrow, or "Zeus commands me to eat this," said by a Sage or Progressor who has made an extensive study of Zeus's commands, i.e. the patterns of nature. It is reasonable if and only if it has the preponderance of reasons in favor of it being true. The standard of reasonableness that makes it reasonable is the reason of the Sage, not the reason of an ordinary civilian on the street (i.e. it is not the legal doctrine of "the reasonable person"). A judgment like "It is reasonable that I shall be alive tomorrow" is not the kind of judgment that the Stoics referred to as a reasonable judgment; it is a judgment about the reasonableness of its inner contents. So it is possible for "It is reasonable that I shall be alive tomorrow" to be a true and kataleptic judgment, even when "I shall be alive tomorrow" is false; the judgment about reasonableness is not falsified by the falsification of the reasonable judgment. The Sage and the Progressor, in the Mathie-Conley reconstruction, do not make any reasonable judgments, only judgments about reasonableness. 
when new information shows that the proposition that they judged to be reasonable turns out to be false (as well as reasonable), i.e. even when later events reveal that Zeus commanded that they be ill, not that they be healthy. This is a consequence of the fact that the standard of reasonableness with reference to which an action is kathekon or not, is the judgment of a Sage at the time of the formulation of the impulse. (And this is the standard no matter what sort of agent performs the action). The Sage at the time of the formulation of the impulse (which will usually coincide with the initiation of the action) is an idealized but finite epistemic agent. Sages have no false beliefs, and they have knowledge (of a very demanding sort) about what things happen by nature (where this includes the social roles of human beings). They also have an ample supply of kataleptic impressions about their surroundings, supplemented with further kataleptic impressions of what it is reasonable to believe about their surroundings and about the future. However, they are certainly not omniscient, and they are not prescient: they do not know any future contingents.

The standard of reasonableness, then, comes to this: if a Sage were to consider my position, having all and only the knowledge that a Sage can have, would they judge it reasonable that Zeus commands me to phi? If so, then it is kathekon for me to phi (regardless of my own motivations, intentions, or reasons for phi-ing). For instance, suppose that I am trying to decide whether to pursue health or illness, and there is nothing unusual about my situation. In this case, the Sage would judge that it is reasonable that Zeus commands me to pursue health. The basis of this judgment would be, for instance, the fact that Zeus himself has disposed me to select health, as well as the lack of any anomalous indications to the contrary. ${ }^{35}$ The Sage's judgment is the best-informed, most knowledgeable, best-considered judgment that any possible finite (non-prescient) agent could make. ${ }^{36}$

35. Should this lack be explicitly recognized among the premises? E.g. after the first $n$ premises listing the relevant considerations, ought there to be a premise that says, "and there are no further relevant considerations"? Probably not; that way lies regress or paradox. Of course, a deliberation can be flawed by its failure to consider all of the relevant considerations, but it is more important for a deliberation to have the virtue of comprehensive consideration than for it to declare such a virtue, just as it is more important for an argument to be in Modus Ponens than for it to have a premise declaring the validity of Modus Ponens.

36. Here I disagree with Klein when he writes: "The sage's assents must be rational not in relation to the principles of orthos logos all things considered, but in relation to what she is in a position to know about them. If this is so, it must sometimes be the case that a virtuous action is not the action that would be virtuous if every relevant consideration could be taken into account. Or to put it slightly differently, the virtuous course of action for a sage will often, and almost perhaps always, be a course of action that in light of further considerations would not be virtuous at all." I disagree that an action could be virtuous to begin with, if it was not reasonable in light of "every relevant consideration," where this means "every consideration that an ideal finite human agent could have access to at the time of decision." 


\section{Consequences of the Mathie-Conley Model of Deliberation}

One of the features of my students' proposal that I find especially elegant is the way that it first introduces the "eulogon" operator, and then later detaches it. The first premises are not qualified as merely "reasonable": they are direct observations of the agent's current circumstances, or theorems of physics. The final conclusion is also not qualified by the reasonable operator: if it were, it would not be an impulse. Instead, the reasonable-operator is introduced at the stage when the Sage moves from the assembly of signs, to the conjecture about Zeus' command, and it is introduced in accordance with the definition of the reasonable axioma. And then it is removed by means of the definition of the kathekon itself.

This model also introduces the kathekon operator only after the agent has arrived at an all-things-considered judgment about what Zeus is likely to have commanded, and this solves a problem that worried me when I wrote for the Cambridge Companion. ${ }^{37}$ When I thought that impulsive content and evaluative content always occur together-roughly, when I espoused the Central Tenet and its converse-then it seemed to me that there was no room for the circumspect consideration of alternatives. As I wrote:

I have suggested that impulses, which certainly do have evaluative content, are per se practical, and sufficiently so, i.e., that they do not need any further item in order to produce action. But then it is not clear how the Stoics can make room for evaluative thoughts formulated in the course of a deliberation that will be properly tentative and not lead headlong to action at a premature stage... For the Stoics, some intrinsic motivational force seems to be built into the very having of evaluative thoughts, and this makes it hard to accommodate deliberation...

Now I find it easy to spot my mistake: it was the assumption that impulse follows directly on evaluation, that one cannot think of something as valuable (good or promoted) without thereby thinking it kathekon to pursue it. But the sample deliberation shows that this was wrong. I can have

Only such considerations-not facts that emerge later-are relevant to establishing the reasonableness of a defense. The "further considerations," it seems to me, could not show that the Sage's action was not virtuous. It could show that Zeus had commanded the Sage to be ill, when the Sage had judged that it was reasonable that Zeus commanded him to be healthy. But discovering that the reasonable turns out otherwise is not discovering that it was not reasonable. What the Sage thinks reasonable will sometimes, in light of further considerations, turn out not to have been true. But it will still have been reasonable, since the standard for reasonableness is the totality of information available beforehand, not information that emerges later.

37. Brennan 2003, p. 280. 
many thoughts to the effect that food is promoted, that illness is demoted, and so on, prior to having any thought about what is kathekon-and only that last thought leads to any impulse.

So at least as far as selection and axia are concerned, I now accept that one can have evaluation without impulse (i.e. "this food is a promoted" without any thought that it is kathekon for me to pursue it), as well as impulse without evaluation (i.e. "I should pursue this food", where "should" does not supervene on a value-judgment; cf. my recantation above). ${ }^{38}$

Perhaps with pathe things are different. They are certainly different in that the evaluation is necessary for the impulse (since the attribution of goodness or badness is partly constitutive of its being an impulse of that sort, e.g. an epithymia). And perhaps they are different in that the evaluation is sufficient for the impulse. On the one hand, this would make the deliberations of the vicious hard to explain, in the way that I worried about earlier: if the very thought that something is a good leads inexorably to the thought that it is kathekon to pursue it, then how can one contemplate alternative goods without rushing this way and that? On the other hand, perhaps it is an advantage, rather than a disadvantage, that this analysis predicts that the deliberations of the vicious will be impetuous and characterized by the alternation of strong impulses, as one desire or fear succeeds another, rather than being properly dispassionate processes in which a full consideration precedes the formulation of any impulse. For vicious people, the closest that they can come to dispassionate deliberation would be something very like the Stoic analysis of akrasia, in which there is a rapid alternation of incompatible impulses, leading to childish, tempestuous behavior (Plutarch, virt. mor. 446 F-447 A).

The model is also illuminating, I think, in that it juxtaposes and reconciles two aspects of the kathekon that sometimes seem to point in separate directions. One is the ethical aspect in which the kathekon is the objective norm or standard of conduct: the parent of officium, and grandparent of die Pflicht. The other aspect is that in which the kathekon is an amoral psychological passe-partout, the ubiquitous content of any and every impulse, no matter how vain or vicious. No impulse to action can eventuate unless the agent thinks of the action as kathekon-as Epictetus tells us, thieves and robbers all act from the impression that their action is kathekon. ${ }^{39}$

What this reconstruction shows, however, is how these two aspects come together in the psychology of the ideal agent. From the standpoint of

38. This also means that the status of food as a promoted indifferent does not need to vary from one context to another; it is promoted on each occasion, whether it will be kathekon to pursue it or not at that time. Confirmation of this comes from the fact that there is a category of kathekonta kata peristasin, but no category of proegmena kata peristasin.

39. E.g. Encheiridion, $₫ 42$. 
teleology, ideal agents will be motivated to act when and only when it is in fact objectively correct for them to act. And non-ideal agents perform vicious actions exactly when their beliefs about what is kathekon fail to be true. That might in one way seem like a platitude-people do the wrong thing because they have false beliefs about what is right-but it is not a platitude. It is an axiom of certain sorts of rationalism or intellectualism, but many philosophers, from Plato to Augustine to Hume, would disagree with it.

\section{Relations to the Lazy Argument}

Another point emerges when one considers the formulation of 5), i.e. the premise of the practical syllogism that invokes the definition of the kathekon. It might seem very strange to formulate an impulse to phi in response to the belief that Zeus has commanded me to phi. For the will of Zeus simply is providence and fate and the series of causes; it is the same as the law that commands and forbids all things. If Zeus wills that I should phi, and Zeus commands me to phi, then I am fated to phi; and if I am already fated to phi, why should I have an impulse to phi?

This, of course, is the Lazy Argument, and I think it is an advantage of the current interpretation that it makes it very easy to see why the opponents of the Stoics raised this objection. We can also see, from this vantage, how the Stoics would answer one variation on the Lazy Argument.

Incompatibilists about deliberation sometimes argue that determinists cannot properly account for human action, because they cannot do justice to the difference between deliberation and discovery. Deliberation (the incompatibilist says) requires that the future be genuinely open and unfixed: we deliberate under the idea of freedom. If the future is already fixed, if what will be true after we act was always going to be true, then we can only discover the future, not create it. But if deliberating about what to do really is a different activity from predicting what (it is already determined that) we shall do, then the future must not be determined.

Whether one thinks that this complaint is a cogent one will depend on one's general views about whether deliberation is compatible with determinism. But the Stoic response can now be put in new terms: they will deny that there is any deep difference between the activity of deliberation and the activity of predicting my own future actions. When a Sage deliberates, they simply try to predict, as closely as their lack of prescience will permit, what in fact they will do. And then they try to conform their impulses to that prediction. Since the future is unknowable, the best prediction comes from the observation of nature, both cosmic nature and human nature, which tells us what we are most likely to do by telling us what it is most natural for us to do. It is an imperfect method of prediction, 
and as a result our impulses, even our most reasonable ones, are sometimes frustrated. But if we knew already what we would do in the future, then we would turn our impulses to doing that very thing. This line of thought shows a different side to the famous Foot Fragment (Epictetus, 2.6.9): it is also a repudiation of the incompatibilists' slogan that deliberation and prediction are fundamentally different kinds of activities. They are not fundamentally different, says Chrysippus: rational deliberation is just prediction without prescience.

But then we can also see a new way of thinking about the telos, and its evolution among the scholarchs. My end, says Chrysippus, is to live according to my experience of what happens by nature. And we have seen that thought illustrated above in the idea that I deliberate by trying to discern what Zeus commands. Now Zeus's laws, the laws of nature, are imperative; they prescribe and prohibit, ordering and forbidding. ${ }^{40}$ But impulse, too, is essentially imperative: it too prescribes and prohibits. ${ }^{41}$ When I succeed in predicting what I shall do, and have an impulse to do it, then my imperative says the same thing that Zeus's imperative does: “do thou eat!" for instance. This is one way of understanding the homologia and symphonia that are so central to Stoicism: what it means for me to live in agreement is that I say the same thing that Zeus does. Diachronic consistency is not the issue: it is not important that I should say the same thing today that I said yesterday. Quite the opposite: I should strive to be just as erratic and anomalous as Zeus is, by striving to order myself to do, at any given time, whatever I have best reason to think that Zeus commands me at that time. ${ }^{42}$ And I thereby experience that homoiosis theo(i) that Plato introduced in the Theaetetus.

But as a human being, who must lack prescience, it will frequently be the case that I cannot accurately predict what Zeus' command will be. I have an impulse to be healthy, but Zeus commands me to be ill. The command that I give myself is in conflict with the command that Zeus gives me, and this conflict is a failure to agree with the nature. Is it also a failure to attain my end? So long as my end is "to live in agreement with nature", then these disagreements do constitute a failure to attain my end. And these disagreements are inevitable for a finite, non-prescient human being. Even the ideal human agent, the Sage, could not live a life of agreement on these terms.

40. SVF 3.314; 3.325; D.L. 7.87

41. Plutarch, Stoic. repugn. 1037F.

42. Of course, much of my evidence for predicting God's commands will come from my past experience of nature. The experience, when developed into a systematic and consistent science, will be my virtue of Physics, and my knowledge of nature. On this see Menn 1995 passim. 
But an end that it is impossible for even an ideal human agent to live starts to seem like it is not a human end at all, not an end for a human being. This, I think, was the reason why Chrysippus amended the telosformulae of Zeno and Cleanthes very slightly: the end is no longer agreement with nature itself, but rather agreement with our experience of nature. This standard, of agreement with our experience of nature, is not an easy standard to achieve (only a Sage can do it) but it is at least humanly achievable. ${ }^{43}$

\section{Apologismos and Apologia}

The definition of the kathekon tells us that the kathekon is what has or can have a reasonable defense or justification. I have said a few things about what I think the qualification "reasonable" amounts to, and how it is supposed to function. Now let me offer some conjectures about what a defense is.

I have already said that I think the canonical defense of an action phi is "Zeus commands me to phi". That is why an argument showing that it is reasonable to think that Zeus commands me to phi constitutes a reasonable defense of phi-ing, i.e. shows that phi is kathekon. Why might the Stoics have thought that this was a good way to defend an action?

Perhaps this was another inheritance from Socrates. Socrates gave an apologia of his actions. And one central element of his apologia consisted in his saying that he had been trying, for some time, to figure out what God had commanded him to do. And he had come to believe, as the result of investigation, that God had commanded him to philosophize and engage his fellow-citizens in elenctic enquiry. He says that he has been stationed and commanded to philosophize by God (tou de theou tattontos), in the

43. I wrote about tailoring our impulses so that they conform to what we can know about "God's general and law-like intentions for things like me" by "living in accordance with our experience of how things happen by nature" in Brennan 2000, p. 176. Ian Hensley is writing a longer paper on the subject of Chrysippus' revision of the earlier telos-formulae, and he points out to me the importance of the word "eiothen" in D.L. 7.88: we are not told to avoid doing what the koinos nomos, the orthos logos, and Zeus himself actually forbid, but rather what they eiothen apagoreuein, what they typically or habitually have forbidden. What Zeus will actually forbid, tomorrow, is not knowable by a human being. But what Zeus is accustomed to forbid, what he has typically forbidden in the past, is one part of the subject of natural science. I also wonder whether "akolouthia" may have been introduced by Chrysippus for similar reasons. If to live homologoumenos te(i) physei means to live in actual, extensional conformity to nature, then to live akolouthos te(i) physei, by contrast, might mean to live "attentively to nature", i.e. paying attention to nature, listening to it through natural science, and attempting to follow it. That akolouthia introduces some notion of intensionality is suggested by Epictetus' use of parakolouthia in Diss. I. 6, 12-21 and elsewhere. 
same way that his military commanders stationed (etatton) him in battle, and he cannot leave that station (taxis). ${ }^{44}$ The Athenians did not accept Socrates' particular defense because they did not believe that Socrates had been commanded by God in the way that he claimed. But the Athenians probably agreed with Socrates about the general principle, that a command from Zeus provides a sufficient defense and justification of one's action.

The language of taxis is very prominent in the Stoic sources, as well. Not only are the commands of Zeus themselves described as prostaxeis, but Cleanthes also asks Zeus and Pepromene to lead him to the place where they have stationed him (bopoi pot' hymin eimi diatetagmenos). ${ }^{45}$ If he is good, then he will follow, and take his stand readily in the place he has been stationed. He will match his own internal prostaxis, his impulse, to the external prostaxis of Zeus, and the diataxis to which Zeus has assigned him.

\section{From the Katbekon to the Telos, for Sages and Progressors}

The model of deliberation sketched out above still needs to be integrated into an account of the agent's end. It is one thing to show that an action is defensible, and quite a different thing to show that it can rationally be done for the sake of the agent's telos and eudaimonia. To argue in a court of law that it is not illegal for me to paint my house blue or throw my rubbish in the street is a very different thing from arguing that those actions are constitutive of a blessed and happy life. ${ }^{46}$

How, then, does the practical syllogism, which shows that an action is kathekon, fit into a larger account of the agent's end? And how, moreover, can we give an account which will work for Sages and also work for Progressors, who are not in a position to be able to perform virtuous actions? The short answer is: by performing the kathekon, both Sages and Progressors can act in accordance with nature, and do this for the sake of the end.

\section{Acting According to Nature, Living According to Nature}

We must make several distinctions. First, a life should be understood as a sequence of actions and impulses. And a life is in accordance with nature if and only if the actions and impulses that constitute it are in accordance with nature. But actions and impulses that are in accordance with nature

44. Plato, Apology, 28e.

45. Quoted by Epictetus at Diss. 4.1.131 and Ench. 53.1.

46. Socrates' speech in court combined the claim that he had been commanded to philosophize by God with the claim that a life devoid of this activity is not worth living. But surely the combination of these two arguments was not typical of Athenian courtroom defenses. 
do not necessarily correlate with the possession of things that are in accordance with nature. One can have an impulse towards health and yet become ill. And one can act on unnatural impulses to be ill, and yet possess health. So the actual possession of things in accordance with nature is irrelevant to the naturalness of one's actions and impulses. And since a life is nothing more than a certain structured collection of actions and impulses, it follows that a life in accordance with nature or our experience of nature, should not be understood as a life in which one possesses the things according to nature. So too for the imperfect or pro tanto cases: whether a life is more in accordance with nature or less in accordance with nature is not measured by what proportion of the time we possess things that are according to nature. Rather, it is measured by what proportion of our pursuits and avoidances are in accordance with nature.

And here the second important point is that to describe something as "according to nature" can either be to describe the input to a deliberation or to describe the outcome of a deliberation. When the Sage surveys all of the promoted and demoted things that are present or in prospect, as well as all of the roles played by the relevant people, this is a survey of what things are according to nature and contrary to nature. And at this stage, the integrity of the Sage's limbs (for instance) is unambiguously promoted and in accordance with nature, and the mutilation of the Sage's limbs is unambiguously demoted and contrary to nature. But that is only one of the many considerations that the Sage has in mind when deliberating. And in weighing all of the many things that are natural or contrary to nature, and in attempting to conjecture about Zeus's commands, the Sage may come to the conclusion that the thing to do is to cut off his or her hand. Let us suppose that it is diseased, and that when the hand is weighed against the arm, and the life, and the obligations to taking care of elderly parents, and so on, it becomes clear that it is kathekon to cut it off. At this stage, in the conclusion of the practical syllogism, we should say that this particular act of mutilating a limb is according to nature, using that phrase now in the conclusory sense. That this act of mutilation can be described, in his case, as "in accordance with nature", is entailed by the fact that the Sage selects it, virtuously, and does so as part of a virtuous life, and to live according to virtue is the same thing as living according to nature.

So there are two kinds of reasons why a life could be filled with continuous disease (for instance) and yet still be a life according to nature, even in respect of health, even while we reaffirm that health is according to nature and disease is contrary to nature. First because what makes a life natural is not the naturalness of the things possessed in it, but the naturalness of the objects of the impulses and actions that constitute the life. If one always chooses what is according to nature, then one is living a life according to 
nature, even if one's choices are frustrated and one comes to possess things contrary to nature. But secondly, because the naturalness of the impulses and actions is not straightforwardly determined by whether the objects of the impulse are natural in the sense of being promoted, i.e. the sort of naturalness that we can identify before doing any complex deliberation and weighing. An impulse is natural in the conclusory way just in case it is directed towards the same object (e.g. amputation) that a Sage would choose, after weighing all of the many signs about what things are promoted and demoted, or natural and contrary to nature in a preliminary rather than a conclusory way. ${ }^{47}$

So I have distinguished a life in accordance with nature from a life in which one possesses the things in accordance with nature, and I have distinguished preliminary or input naturalness from conclusory or output or all-things-considered naturalness. To live according to nature, it is not necessary that you succeed in acquiring objects that are according to nature, and it is not even necessary that you pursue things that are according to nature in the preliminary way (sc. promoted things).

Next, I think it is important that acting according to nature (prattein kata physin) is something that one can accomplish more easily than living according to nature. The second, living according to nature, is something that only Sages do. But the first is something that Progressors can do, as well. Epictetus' beginners are sometimes able, at least for a brief time, to keep their prohairesis in a natural state. If they could do that constantly and unfailingly and from a strong and inflexible disposition, then they would be wise. And that is far beyond them. But at least for today, for this trip to the bath, they can try to perform one or two actions that are natural.

In this regard, I propose, acting according to nature is like several other Stoic concepts, is being common to Sages and Progressors: katalepsis, for instance, or ekloge or the kathekon itself. In each case, both Sages and nonSages can perform individual tokens of cognition or selection or proper functions, and indeed every non-Sage will inevitably perform many tokens of each. But there is another very important fact about these common actions. In some sense, the Sage's virtuous life is composed of nothing more than the very actions that the non-Sage, too, can perform. A Sage's life is, in one sense, nothing more than a lot of kathekonta, and a lot of eklogai, and a

47. I want to see if the distinction between the preliminary identification of (e.g.) health as natural as an input to deliberation versus the conclusory identification of (e.g.) mutilation as all-things-considered natural at the end of a deliberation might help us to understand the occasional references to ta prota kata physin. The priority there might not be that of moral development (as though the prota are the ones we find natural already in the cradle), nor of logical priority, but of whether the designation is intended to apply before or after deliberation. More study needed. 
lot of katalepseis. But where the non-Sage performs them erratically, and irregularly, and from an unstable disposition, the Sage performs them constantly and without exception, and from the right sort of strong disposition. These additional properties that make the kathekonta into katorthomata, or make the mere katalepseis into episteme, might be called "overarching" features, because they act somewhat like the form of the arch. There is, in one sense, nothing more to an arch than a lot of stones, and any particular stone in an arch could equally well be a stone in a random heap of stones ${ }^{48}$. What makes the stones into an arch, and thus gives the collection of stones new powers, is something about the larger pattern that they exemplify, and how each one relates to the rest. ${ }^{49}$

This makes the conceptual difficulty of becoming a Sage far more tractable than it may seem when considered in light of the extreme dichotomy between Sage and non-Sage. It is of course extremely difficult in practice. But the theory is simple: as a non-Sage, you can already perform kathekonta, employ katalepsis and ekloge, and act kata physin. To become a Sage, you only need to do more of that, and do it more regularly. And eventually, you need to do it exceptionlessly, and do it from the right disposition, as well. And yet, there is nothing more that is needful for Sagehood than the performance of many tokens of these, in the right sort of exceptionless pattern, from the right sort of firm and strong disposition. The non-Sage sometimes acts according to nature. The Sage also acts according to nature, and really does not do anything other than acting according to nature; however, the Sage's acting according to nature is so regular, exceptionless and rooted in their disposition that they can be said to live (not merely act) according to nature. The non-Sage sometimes performs kathekonta. And the Sage also performs kathekonta; however, the Sage's performance of kathekonta is so regular and exceptionless and so on that they can be said to live in the complete performance of all of the kathekonta, as Archedemos said in describing the telos. And so too for the formulae of Diogenes and Antipater: each of the post-Chrysippean telos-formulae show the same pattern, that the Sage's life consist of nothing more than the continuous and exceptionless performance of a class of common actions, any one of which a non-Sage may also do.

This means that both the Sage and the non-Sage can perform the actions that deliberation identifies, not only because they are kathekonta, i.e. plausibly in conformity with the will of Zeus, but also for the sake of their

48. It could even be the same stone at the same location in space that it would have occupied in the arch, and oriented in the same orientation, but surrounded by a chaotic jumble of other stones.

49. An early use of the analogy of arches and key-stones can be found in the pseudoAristotelian de Mundo, 399b29-33, but its date is uncertain. 
own happiness. When a Sage deliberates about what to do, and identifies something that it is reasonable that Zeus commands, then it also becomes apparent to them that doing this action is constitutive of their living in accordance with virtue, and is thus an imminent good, a benefit, and constitutive of a happy life.

When Progressors identify the kathekon action, they cannot hope to enjoy an imminent good by its performance: its performance is, in itself, an indifferent, and makes no contribution to happiness. However, the Progressor can still perform the action for the sake of their own happiness, and this for two reasons. First, the performance of these indifferent actions is a sine qua non of future happiness: Stobaeus, 2.86. 12-16, tells us that if we do not perform them, then we will not be happy. And if I believe that $\mathrm{E}$ is my end, and $S$ is a sine qua non for the realization of $E$, then I can perform $S$ for the sake of $\mathrm{E}$, even if I do not think that $S$ is any part of $E$, or causally produces $\mathrm{E}$, or is instrumentally productive of E. Secondly, I can perform the action for the sake of my future happiness, because I can believe, truly, that this action is of a sort (the kathekon) such that happiness does consist in nothing but performing actions of this sort, organized into the right overarching pattern, and that by performing it I will be coming closer to acquiring the abilities needed to organize the actions correctly. If my end is to build an arch, then I have good reason to practice piling up stones, even if I am not yet in a position to accomplish the particular kind of stonepiling that is constitutive of arch-building. If my end is to play a concerto on the piano, then I have good reason to practice playing individual notes and chords on the piano, even if I am not yet in a position to play a concerto, both because in one sense there is nothing more to playing a concerto than playing a lot of individual notes and chords in a particular organization, and because only by practicing now can I come to acquire the ability to bring the notes together into an overarching concerto form.

Thus, whether I am a Sage or not, I can rationally and clear-headedly perform these actions for the sake of my end. As a Progressor, I do not need to have the false belief that my activity right now is a good of any sort in order to think that my activity is for the sake of my good.

\section{Abandonner une partie d'échecs}

Finally, I would like to say something about times when an agent selects something that is typically contrary to nature, or not promoted. Suicide is of course the most notorious example of this sort of choice, but presumably any time that one chooses to go hungry or jeopardize one's health or embrace poverty, one is selecting a demoted indifferent. One does so, in each case, because one concludes from a survey of the available evidence that it is reasonable that this is what Zeus commands. But since the default assum- 
ption should always be that Zeus commands me to pursue the promoted indifferent, what could constitute sufficient evidence that this was not true in a particular case, aside from the actual frustration of an impulse to pursue the promoted? If I set out for the grocery store and my car breaks down on the way, is that a sufficient sign that Zeus commands me not to acquire food? Or does it simply show me that Zeus wants me to take the bus? If I take the bus and the bus breaks down as well, should I now conclude that Zeus wants me to fast, or that he commands me to continue the journey on foot?

If the rule is that I should pursue promoted things and things in accordance with nature until it is literally impossible that I will acquire them, then I will never extinguish my impulses in time to have new impulses for the outcomes that occur-I will never desire illness until I am actually ill, nor will I ever resign myself to death until I am actually dead. If I must struggle for life until life is impossible, then suicide becomes impossible, too. ${ }^{50}$

So this must be the wrong model. A better model, I think, is the one suggested by our discussion of deliberation: I survey all of the relevant facts, and then try to formulate a reasonable conjecture about Zeus's commands. A skilled practitioner of the art of life, I think, will approach these questions in the way that a skilled chess-player approaches the decision to resign from a game. A good chess-player does not postpone their resignation until it is literally impossible to win. After all, it will very seldom be true that the remaining pieces on the board make it literally impossible for one player to win, i.e. that there is no sequence of legal moves that would result in a win. A player who played on until this was true would be considered a very poor player, a very gross player who lacked all subtlety, finesse, and delicacy of perception, and whose conduct was also an insult to their opponent. Instead, a good player finds himself at a crucial juncture in a game-perhaps after the unexpected loss of an important piece-and surveys the likely developments. He considers his own resources-pieces, position, and personal ability — and considers the resources of his opponent. He thinks through the next few rounds, and considers how they are likely to evolveor perhaps he thinks through many possible future rounds, but surely not all of them. And what he sees is a general diminution of possibility, an indeterminate sense that there is only attrition, constriction and loss in the future, although which particular game would be actualized if play were to continue is far from clear. This prediction is based on years of playing, thousands of games, and a broad experience of what things happen in chess. It is not knowledge of the future, but it is a reasonable prediction about the

50. This "extinguishing" of an impulse for the promoted thing, and its replacement by an impulse for its opposite, is what Brunschwig studied so brilliantly under the title of "renversement;" see Brunschwig 2005. 
future. Resigning a game at the right time, neither too early nor too late, is an expert move itself; it shows respect for one's opponent, and brings credit on oneself.

Something like this must be what goes into the Sage's decision to pursue something contrary to nature, whether a trivial inconvenience or death itself. 
BIBLIOGRAPHY

BRENNAN, Tad 1996: "Reasonable Impressions in Stoicism', Phronesis, 41 (1996), p. 318334.

- 1999: "Demoralizing the Stoics", unpublished paper delivered to the Boston Area Colloquium on Ancient Philosophy, 1999.

- 2000: "Reservation in Stoic Ethics" Archiv für Geschichte der Philosophie, 82 (2000), p. 149-177.

- 2003: "Stoic Moral Psychology", in B. Inwood (ed.), The Cambridge Companion to the Stoics, Cambridge, 2003 (Cambridge Companions to Philosophy), p. 257-294.

- 2005: The Stoic Life: emotions, duties, and fate, Oxford, 2005.

BRUNSCHWIG, Jacques 2005: "Sur Deux Notions de l'Éthique Stoïcienne: de la 'Réserve' au 'Renversement'," in G. Romeyer Dherbey, J.-B. Gourinat (eds.), Les Stö̈ciens, Paris, 2005 (Bibliothèque d'histoire de la philosophie), p. 357-380.

KLEIN, Jacob 2010: Nature and Reason in Stoic Ethics, unpublished dissertation, Ithaca Cornell University, 2010.

- 2012a: "Stoic Eudaimonism and the Natural Law Tradition," in J. Jacobs (ed.), Reason, Religion and Natural Law: Historical and Theoretical Studies, Oxford, 2012, p. 57 80 .

- 2012b: "Stoic Thinkers," in T. Angier (ed.), Ethics: The Key Thinkers, London, 2012, p. 57-82.

— forthcoming: "Of Archery and Virtue: Ancient and Modern Conceptions of Value," Philosophers' Imprint, Ann Arbor Michigan.

Menn, Stephen 1997: "Physics as a Virtue," in J. Cleary (ed.), Proceedings of the Boston Area Colloquium on Ancient Philosophy, 11, Lanham, 1997, p. 1-34. 